\title{
PREPARAÇÕES PROBIÓTICAS UTILIZANDO POUPA DE BANANA E Lactobacillus Acidophilus EM FERMENTAÇÃO SÓLIDA
}

\author{
H. GONCALVES ${ }^{1}$, S. R. FERREIRA ${ }^{1}$ e U. COUTINHO FILHO ${ }^{1}$ \\ ${ }^{1}$ Universidade Federal de Uberlândia, Faculdade de Engenharia Química \\ E-mail para contato: hemelyg@hotmail.com
}

\begin{abstract}
RESUMO - Considera-se inquestionável que os probióticos sejam produtos cada vez mais utilizados por sua ação na defesa do organismo contra infecções, prevenção do câncer e reconstituição da flora intestinal humana, porém, tem-se que produtos lácteos nem sempre estão disponíveis para grande parte da população brasileira e nem sempre são utilizados nos hábitos alimentares da mesma. Assim, a busca de novas formulações probióticas possibilita fazer com que os benefícios já comprovados da alimentação com probióticos possam ser direcionados à população de forma mais eficaz. Dessa forma, utilizou-se a espécie Lactobacillus Acidophilus que é reconhecida segura para o consumo (GRAS), podendo ser usada em processos com condições variáveis, como temperaturas entre $2^{\circ}$ e $53^{\circ} \mathrm{C}$. Sendo assim, foram realizadas fermentações sólidas com concentração celular inicial de $10^{6}$ células/g em meio MRS e a seguir foram feitas avaliações da concentração celular. Os resultados se mostraram insatisfatórios em relação ao uso da banana até o presente momento.
\end{abstract}

\section{INTRODUÇÃO}

A crescente preocupação em se ingerir alimentos saudáveis, que favoreçam o bem estar e auxiliem na redução de doenças, amplia a demanda por alimentos funcionais com especial atenção para os probióticos que são cada vez mais utilizados por sua ação direta e indireta na defesa do organismo contra infecções, prevenção do câncer e reconstituição da flora intestinal humana (CORRÊA, 2006; FLINT, ANGERT, 2005).

Entre as bactérias probióticas utilizadas destacam-se as lácticas, capazes de se desenvolver em diversas condições e ambientes. É possível encontrá-las, principalmente, em alimentos fermentados, como leite, carnes, vegetais, grãos, frutas e bebidas, porém algumas destas bactérias fazem parte da microbiota natural dos sistemas digestivo e respiratório, existindo a possibilidade de encontrá-las também nas cavidades naturais de humanos e animais. Uma atenção maior é dada as bactérias do gênero Lactobacillus, que serão utilizadas neste trabalho.

As bactérias do gênero Lactobacillus são usadas na preparação de formulações probióticas para uso animal e humano. Neste gênero a espécie Lactobacillus Acidophilus, que será utilizada como objeto de estudo neste projeto, se destaca, pois este é reconhecido como seguro para o consumo (GRAS) e pode ser usado em processos com condições variáveis 
como temperaturas entre $2^{\circ} \mathrm{C}$ e $53^{\circ} \mathrm{C}$ (CHARTERIS et. al. 1997; GOMES E MALCATA, 1999; SAARELA et. al. 2000).

Neste contexto, os produtos lácteos, como leites fermentados, bebidas lácteas, iogurtes, dentre outros, representam a maior parte do mercado de alimentos probióticos. Além disso, há o interesse, da indústria e por parte dos indivíduos, de novos produtos probióticos, pois os derivados probióticos do leite nem sempre estão disponíveis para grande parte da população brasileira e nem sempre são utilizados nos hábitos alimentares desta população (MARTINS et. al. 2013).

Devido à razões financeiras, hábitos alimentares diferenciados e possíveis problemas de saúde, parte da população tem optado cada vez mais por uma dieta sem leite. Tal situação pode ser verificada de várias formas como, por exemplo, pela exigência médica rotineira, associada à obesidade, exigindo que o leite e derivados tenham seu consumo reduzido com o objetivo de favorecer a alimentação, reduzindo calorias e colesterol, e hábitos vegetarianos que, para muitos, restringe não só o consumo de carnes, mas também o consumo de derivados de origem animal como queijos, iogurtes e leites fermentados.

Sendo assim, a procura de novos alimentos com probióticos que não sejam produtos derivados do leite representa uma pesquisa que é justificada através da importância do tema e pela possibilidade de ampliar os benefícios do consumo de probióticos à parcela da população que evita o consumo de leite. Neste contexto, o interesse por formas de alimentos de fácil acesso a população como, por exemplo, preparações com polpas de frutas, amplia ainda mais a importância deste tipo de estudo.

Muitas espécies de plantas são reconhecidas por sua ação bioativa e sua ação potencial contra doenças crônicas e muitas outras no mundo não foram estudadas até o momento. $\mathrm{O}$ Brasil é um dos países com a maior diversidade de plantas nativas no mundo: são 40.000 espécies, representando $20 \%$ da flora mundial. No entanto, a riqueza das plantas brasileiras é apenas parcialmente conhecida devido a problemas históricos e socioeconômicos. Assim, a existência de muitas espécies não estudadas tem motivado pesquisas para descobrir o potencial nutricional e medicinal de frutas, folhas e cascas das plantas (OLIVEIRA et. al., 2012).

Frutas são ricas em compostos bioativos, antioxidantes e fibras, essenciais para uma dieta balanceada e uma perda de peso de forma saudável, além disso, são apropriadas para melhorar a qualidade de vida (HERVERT-HERNÁNDEZ et. al., 2011). A demanda de frutas tem aumentado devido ao interesse maior das pessoas no cuidado com o corpo e na prevenção de doenças. Assim, a escolha de frutas não é feita de acordo com características sensoriais, mas pela relação entre dieta e saúde. (YAHIA, 2010).

Para o presente trabalho, fez-se uso da banana como fruta, devido ao fato de a mesma ser uma fruta comum, de fácil acesso à população e de baixo custo. Além disso, a banana é uma fruta rica em fibras, potássio, vitaminas $\mathrm{C}$ e $\mathrm{A}$ e ajuda na redução da pressão arterial, no fortalecimento dos ossos, além de ajudar na visão e no funcionamento do intestino. 


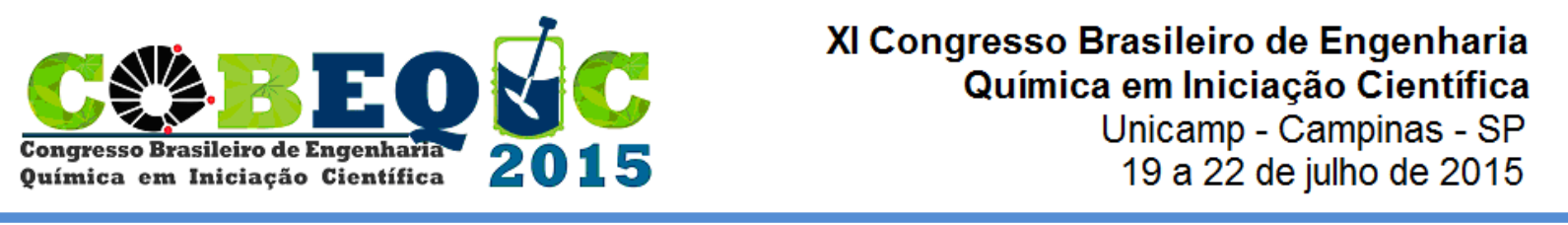

\section{MATERIAIS E MÉTODOS}

\subsection{Micro-organismos e Fermentações}

Foram realizadas fermentações de Lactobacillus Acidophilus LA5 com concentração celular inicial de $10^{6}$ células $/ \mathrm{g}$ em erlemeyer de $250 \mathrm{~mL}$ contendo $100 \mathrm{~mL}$ de meio. Este foi submetido à agitação de $300 \mathrm{rpm}$ em incubador rotativo de $30^{\circ} \mathrm{C}$ por $48 \mathrm{~h}$ em meio MRS, cuja composição encontra-se na Tabela 1 , sendo este otimizado para fermentação probiótica de Lactobacillus Acidophilus.

Tabela 1 - Composição do meio MRS

\begin{tabular}{|c|c|}
\hline Meio & Composição do Meio \\
\hline MRS & $\begin{array}{l}\text { Glicose }(20 \mathrm{~g} / \mathrm{L}) \text {, peptona de caseína }(10 \mathrm{~g} / \mathrm{L}) \text {, extrato de carne }(10 \mathrm{~g} / \mathrm{L}) \text {, extrato } \\
\text { de levedura }(5 \mathrm{~g} / \mathrm{L}) \text {, fosfato de potássio dibásico }(2 \mathrm{~g} / \mathrm{L}) \text {, acetato de sódio }(5 \mathrm{~g} / \mathrm{L}) \text {, } \\
\text { citrato de amônio }(2 \mathrm{~g} / \mathrm{L}) \text {, sulfato de manganês }(0,05 \mathrm{~g} / \mathrm{L}) \text {, sulfato de magnésio } \\
(0,2 \mathrm{~g} / \mathrm{L}) \text {. }\end{array}$ \\
\hline
\end{tabular}

\subsection{Preparação das Formulações Probióticas com Polpas de Fruta}

As preparações foram realizadas a partir de células fermentadas e isoladas por centrifugação, seguida da ressuspensão dessas células em água, sendo que a obtenção das mesmas foi feita conforme descrito no item 2.1. Em seguida, foram adicionadas às células polpa de fruta de banana e glicose. Posteriormente foi feita uma secagem em estufa de circulação forçada e em condições de temperatura de aproximadamente $50^{\circ} \mathrm{C}$ em intervalos entre $12 \mathrm{~h}$ e $48 \mathrm{~h}$, segundo a Tabela 2.

Tabela 2 - Composição das preparações de polpas de fruta

\begin{tabular}{|c|c|c|}
\hline Formulação & Tempo de Secagem & Composição de Formulação \\
\hline 1 & $12 \mathrm{~h}$ & $\begin{array}{c}60 \% \text { de polpa de banana e } 40 \% \text { de solução } \\
\text { de glicose } 10 \mathrm{~g} / \mathrm{L}\end{array}$ \\
\hline 2 & $12 \mathrm{~h}$ & $\begin{array}{c}70 \% \text { de polpa de banana e } 30 \% \text { de solução } \\
\text { de glicose } 5 \mathrm{~g} / \mathrm{L}\end{array}$ \\
\hline 3 & $12 \mathrm{~h}$ & $80 \%$ de polpa de banana e $20 \%$ de água \\
\hline 4 & $24 \mathrm{~h}$ & $\begin{array}{c}60 \% \text { de polpa de banana e } 40 \% \text { de solução } \\
\text { de glicose } 10 \mathrm{~g} / \mathrm{L}\end{array}$ \\
\hline 5 & $24 \mathrm{~h}$ & $\begin{array}{c}70 \% \text { de polpa de banana e } 30 \% \text { de solução } \\
\text { de glicose } 5 \mathrm{~g} / \mathrm{L}\end{array}$ \\
\hline 6 & $24 \mathrm{~h}$ & $80 \%$ de polpa de banana e $20 \%$ de água \\
\hline 7 & $36 \mathrm{~h}$ & $\begin{array}{c}60 \% \text { de polpa de banana e } 40 \% \text { de solução } \\
\text { de glicose } 10 \mathrm{~g} / \mathrm{L}\end{array}$ \\
\hline 8 & $36 \mathrm{~h}$ & $\begin{array}{c}70 \% \text { de polpa de banana e } 30 \% \text { de solução } \\
\text { de glicose } 5 \mathrm{~g} / \mathrm{L}\end{array}$ \\
\hline 9 & $36 \mathrm{~h}$ & $80 \%$ de polpa de banana e $20 \%$ de água \\
\hline
\end{tabular}




\begin{tabular}{|c|c|c|}
\hline 10 & $48 \mathrm{~h}$ & $\begin{array}{c}60 \% \text { de polpa de banana e } 40 \% \text { de solução } \\
\text { de glicose } 10 \mathrm{~g} / \mathrm{L}\end{array}$ \\
\hline 11 & $48 \mathrm{~h}$ & $\begin{array}{c}70 \% \text { de polpa de banana e } 30 \% \text { de solução } \\
\text { de glicose } 5 \mathrm{~g} / \mathrm{L}\end{array}$ \\
\hline 12 & $48 \mathrm{~h}$ & $80 \%$ de polpa de banana e $20 \%$ de água \\
\hline
\end{tabular}

\subsection{Concentração de Células nas Preparações}

A viabilidade celular nas preparações foi avaliada por plaqueamento em meio ágar MRS, sendo que a concentração de células viáveis foi estimada segundo a Equação 1, que descreve a Concentração de células viáveis $(\mathrm{N})$ em função da Contagem realizada $(\mathrm{C})$, do Fator de Diluição (FD), do Volume Total (Vt), obtido pela ressuspensão da massa sólida em solução peptonada a 1\%, do Volume Usado (V) e da Massa da amostra (m) em ensaios com diluições 1:10, 1:100 e 1:1000.

$$
N\left(\frac{c e l}{g}\right)=C \times F D \times \frac{V t}{V} \times \frac{1}{m}
$$

\section{RESULTADOS E DISCUSSÕES}

Foram realizadas contagens das células viáveis em cada uma das amostras com três níveis de diluição: $10^{-1}, 10^{-2}$ e $10^{-3}$, com plaqueamentos realizados nos intervalos de 5,10 e 15 dias. Os resultados estão apresentados na Tabela 3 e Tabela 4.

Tabela 3 - Resultados obtidos através dos experimentos no intervalo de 5 dias

\begin{tabular}{|c|c|}
\hline Ensaio & Células Viáveis (Cél/g) (5 dias) \\
\hline A1 & $7,450 \times 10^{5}$ \\
\hline A2 & $8,920 \times 10^{5}$ \\
\hline A3 & $3,780 \times 10^{6}$ \\
\hline A4 & $9,830 \times 10^{5}$ \\
\hline A5 & $3,952 \times 10^{6}$ \\
\hline A6 & $2,210 \times 10^{6}$ \\
\hline A7 & $4,562 \times 10^{5}$ \\
\hline A8 & $1,409 \times 10^{6}$ \\
\hline A9 & $7,211 \times 10^{4}$ \\
\hline A10 & $3,997 \times 10^{5}$ \\
\hline A11 & $9,830 \times 10^{4}$ \\
\hline A12 & $2,861 \times 10^{5}$ \\
\hline
\end{tabular}

Tabela 4 - Resultados obtidos através dos experimentos no intervalo de 10 dias

\begin{tabular}{|c|c|}
\hline Ensaio & Células Viáveis $($ Cél $/ g)$ \\
\hline
\end{tabular}




\begin{tabular}{|l|l|}
\hline A3 & $1,040 \times 10^{6}$ \\
\hline A6 & $1,448 \times 10^{6}$ \\
\hline
\end{tabular}

Através dos experimentos realizados, observou-se o decaimento gradual da viabilidade celular em todos os ensaios conforme o tempo de armazenamento aumentou, o que sugeriu uma validade de, no máximo, 10 dias e somente para os ensaios A3 e A6, conforme mostra a Tabela 4, considerando que a legislação só permite produtos com viabilidade celular superior à $10^{6} \mathrm{Cel} / \mathrm{g}$ e, no decorrer do tempo, os outros ensaios não estavam de acordo com o permitido.

A comparação entre os resultados obtidos nos ensaios com glicose e sem glicose nos diferentes tempos sugere que o uso da glicose não favoreceu a manutenção das células viáveis, pois nos ensaios sem glicose foi observada uma maior concentração das mesmas.

Referente ao tempo de secagem, observa-se que os tempos de secagem entre 12 e $24 \mathrm{~h}$ geraram maior preservação das células que o obsevado nos tempos entre 36 e $48 \mathrm{~h}$.

\section{CONCLUSÃO}

A partir das informações contidas neste trabalho pode-se concluir que: a) a adição de glicose, independente da concentração da mesma, não favoreceu a viabilidade celular; b) o produto estudado deve ter validade de no máximo 10 dias caso seja armazenado à temperatura ambiente; c) não ocorreu crescimento celular após a secagem.

\section{REFERÊNCIAS BIBLIOGRÁFICAS}

CHARTERIS, W.P.; KELLY, P.M.; MORELLI. L.; COLLINS, J.K. Selective detection, enumeration and identification of potentially probiotic Lactobacillus and Bifidobacterium species in mixed bacterial populations Int. J. of Food Microb. v. 35, n. 1, p. 1-27, 1997.

CORRÊA, S. B. M., Desenvolvimento de manjar branco potencialmente probiótico. Tese de mestrado, Universidade de São Paulo, Faculdade de Ciências Farmacêuticas. São Paulo, 2006.

FLINT „J. F.; ANGERT, E. R. Development of a strain-specific assay for detection of viable Lactobacillus sp. HOFG1 after application to cattle feed Journal of Microbiological Methods, v.61,p.235-243, 2005.

GOMES, A.M.P.; MALCATA, F.X. Bifidobacterium spp. and Lactobacillus acidophilus: biochemical, technological and therapeutical properties relevant for use as probiotics. Trends in Food Science and Technology. v. 10, n. 4/5, p. 139-157, 1999.

HERVERT-HERNÁNDEZ, D.; GARCÍA, O.P.; ROSADO, J.L.; GOÑI, I.; 2011. The contribution of fruits and vegetables to dietary intake of polyphenols and antioxidant capacity in a Mexican rural diet: importance of fruit and vegetable variety. Food Res. Int. $44,1182-1189$. 
MARTINS, E. M. F.; RAMOS, A. M.; VANZELA, E. S.L.; STRINGHETA, P. C.; PINTO, C. L. O.; MARTINS, J. M. Products of vegetable origin: A new alternative for the consumption of probiotic bacteria Review Article Food Research International, v.51, n.2 (2013), 764-770

OLIVEIRA, V.B.; YAMADA, L.T.; FAGG, C.W.; BRANDÃO, M.G.L.; 2012. Native foods from Braziliam biodiversity as a sourse of bioactive compounds. Food Res. Int. 48, 170179.

SAARELA, M; MOGENSEN, G.; FONDÉN, R.; MÄTTÖ, J.; MATTILA-SANDHOLM, T. Probiotic bacteria: safety, functional and technological properties. J. of Biotech. v. 84, p. 197-215, 2000.

YAHIA, E.M.; 2010. The contribution of fruit and vegetable consumption to human health. In: ROSA, L.A.; ALVARES-PARRILLA, E.; GONZALES-AGUILARA, G.A. (EDS.), Fruit and Vegetable Phytochemicals Chemistry Nutritional Value and Stability. WileyBlackwell, Hoboken, pp. 2-51. 